\title{
Temperature stability of $(\mathrm{Pt} / \mathrm{Co})_{3} / \mathrm{IrMn}$ multilayers
}

\author{
L. Lechevallier, ${ }^{1,2, a)}$ A. Zarefy, ${ }^{1}$ F. Letellier, ${ }^{1}$ R. Lardé, ${ }^{1}$ D. Blavette, ${ }^{1}$ J. M. Le Breton, ${ }^{1}$ \\ V. Baltz, ${ }^{3}$ B. Rodmacq, ${ }^{3}$ and B. Dieny ${ }^{3}$ \\ ${ }^{1}$ Groupe de Physique des Matériaux (GPM), UMR 6634 CNRS, Université et INSA de Rouen, Avenue de \\ l'Université, B.P. 12, 76801 Saint Etienne du Rouvray, France \\ ${ }^{2}$ Département de GEII, Université de Cergy-Pontoise, rue d'Eragny, Neuville sur Oise, 95031 Cergy-Pontoise, \\ France \\ ${ }^{3}$ SPINTEC (UMR 8191 CEA-CNRS-UJF-Grenoble INP), CEA/INAC, 38054 Grenoble Cedex 9, France
}

(Received 14 May 2012; accepted 11 July 2012; published online 21 August 2012)

The effect of annealing on the structural stability of $\left(\mathrm{Pt}_{2 \mathrm{~nm}} / \mathrm{Co}_{0.4 \mathrm{~nm}}\right)_{3} / \mathrm{IrMn}_{7 \mathrm{~nm}}$ multilayers has been investigated using atom probe tomography. The composition of individual layers was measured after annealing at $300,400,500$, and $700^{\circ} \mathrm{C}$. While results show that the $(\mathrm{Pt} / \mathrm{Co})_{3} / \mathrm{IrMn}$ stacking sequence is preserved up to $400^{\circ} \mathrm{C}$, there is an almost complete destruction of the multilayered structure when annealing at higher temperatures $\left(500\right.$ and $\left.700{ }^{\circ} \mathrm{C}\right)$. Co layers no more alternate with Pt-rich layers. The whole stack is transformed into an $\mathrm{IrCo} / \mathrm{PtMn}$ bilayer. These results are interpreted on the basis of atomic mobilities and chemical affinities. Diffusion of $\mathrm{Co}$ and $\mathrm{Mn}$ is shown to become important when annealing temperature approaches $500{ }^{\circ} \mathrm{C}$. Results are well accounted for by thermodynamics arguments considering the Co-Ir and Pt-Mn phase diagrams. (C) 2012 American Institute of Physics. [http://dx.doi.org/10.1063/1.4745033]

\section{INTRODUCTION}

Exchange bias effect in ferromagnetic (FM)/antiferromagnetic (AFM) bilayers is macroscopically evidenced by a shift of the magnetic hysteresis loop along the magnetic field axis direction (exchange bias field, $\mathrm{H}_{\mathrm{E}}$ ). This phenomenon finds its origin from exchange interaction between FM and AFM layers across their interface. Optimum loop shift is generally obtained after annealing and field cooling from above the blocking temperature of the AFM layer. ${ }^{1-5}$ During the last decade, these systems have been extensively investigated due to their applications in the development of spintronic devices, such as spin valves and tunnel junctions. Perpendicular exchange bias effect has been widely stud$\operatorname{ied}^{7-11}$ in the context of spin valves or tunnel junctions with perpendicular-to-plane magnetization. ${ }^{12,13}$

Among these systems, $(\mathrm{Pt} / \mathrm{Co})_{\mathrm{n}} \mathrm{FM}$ multilayers exchange-coupled to an AFM layer, such as IrMn or FeMn, have been intensively studied. The perpendicular anisotropy of FM multilayers depends on several parameters, such as the number $(\mathrm{n})$ of $(\mathrm{Pt} / \mathrm{Co})$ repeats or the thickness of the Co and Pt layers. ${ }^{13-15}$ For small Co thicknesses $(0.4 \mathrm{~nm})$, it has been shown that an increase of the exchange bias field $\mathrm{H}_{\mathrm{E}}$ can be obtained by introducing an ultrathin Pt layer between the $(\mathrm{Pt} / \mathrm{Co})_{\mathrm{n}}$ multilayer and the IrMn layer. ${ }^{12,13,16,17}$ This phenomenon has been ascribed to the reinforcement of the perpendicular orientation of the topmost Co magnetization by the introduction of an additional $\mathrm{Co} / \mathrm{Pt}$ interface. ${ }^{13,18}$ Recently, we have shown that in $\left(\mathrm{Pt}_{2 \mathrm{~nm}} / \mathrm{Co}_{0.4 \mathrm{~nm}}\right)_{3} / \mathrm{Pt}_{0.4 \mathrm{~nm}} /$ $\mathrm{IrMn}_{7 \mathrm{~nm}}$ multilayers, the Pt spacer acts as a diffusion barrier, which prevents Mn diffusion into the Co layer in contact with IrMn and thereby also contributes to the reinforcement of the perpendicular anisotropy. ${ }^{19-21}$ In these multilayers,

\footnotetext{
${ }^{a)}$ Email: luc.lechevallier@univ-rouen.fr.
}

$\mathrm{Mn}$ atoms seem to be trapped by the $\mathrm{Pt}$ atoms of the spacer. The $(\mathrm{Pt} / \mathrm{Co})_{3} / \mathrm{IrMn}$ multilayers studied in the above cited papers were generally annealed at a temperature around $250^{\circ} \mathrm{C}$ and field-cooled down to room temperature in order to induce the magnetic exchange anisotropy.

In this work, we investigate the influence of further annealing at higher temperatures on the structural evolution of $\left(\mathrm{Pt}_{2 \mathrm{~nm}} / \mathrm{Co}_{0.4 \mathrm{~nm}}\right)_{3} / \mathrm{IrMn}_{7 \mathrm{~nm}}$ multilayers. Following the initial and usual field cooling at $250^{\circ} \mathrm{C}$, the samples were additionally annealed at four different temperatures (300, 400, 500 , and $700^{\circ} \mathrm{C}$ ) for $1 \mathrm{~h}$. The compositions of the individual layers were subsequently characterized at the atomic scale using laser-assisted atom probe tomography (APT). Comparison of the results allows a deeper understanding of diffusion processes involved in the observed compositional changes.

\section{EXPERIMENTAL: SAMPLES PREPARATION}

$\mathrm{Ta}_{3 \mathrm{~nm}} /\left[\left(\mathrm{Pt}_{2 \mathrm{~nm}} / \mathrm{Co}_{0.4 \mathrm{~nm}}\right)_{3} / \mathrm{IrMn}_{7 \mathrm{~nm}}\right]_{7} / \mathrm{Pt}_{10 \mathrm{~nm}}$ multilayers were deposited onto a $\mathrm{Si} / \mathrm{SiO}_{2} /$ substrate by $\mathrm{DC}$ magnetron sputtering at room temperature, using a $5.3 \times 10^{-6} \mathrm{~Pa}$ base pressure and a $0.25 \mathrm{~Pa}$ Ar pressure during deposition. Layers being very thin, the $(\mathrm{Pt} / \mathrm{Co})_{3} / \mathrm{IrMn}$ sequence was repeated seven times in order to obtain a large enough analyzed volume and to allow an accurate analysis of interfaces by APT. Multilayers were subsequently annealed at $250{ }^{\circ} \mathrm{C}$ during half an hour in a separate oven under a pressure of $10^{-4} \mathrm{~Pa}$ and cooled under a $2.4 \mathrm{kOe}$ magnetic field applied perpendicular to the film plane. This is the usual procedure used to set the exchange bias magnetic properties. ${ }^{2}$ This state constitutes our as-prepared state and will be used as our starting point.

APT is a unique tool able to map out the $3 \mathrm{D}$ distribution of atoms at the atomic scale. The principle of this technique is based on field evaporation of surface atoms from a sample prepared in the form of sharp needles, with an end radius 
less than $50 \mathrm{~nm}$, and on their subsequent chemical identification by time-of-flight mass spectrometry. ${ }^{22,23}$ The evaporated atoms are collected by a time-resolved position-sensitive detector that provides both the time of flight and the position of incoming ions. This combined information allows deducing the chemical nature of evaporated ions and calculating the position from which atoms originate at the tip surface. The $3 \mathrm{D}$ reconstruction of the analyzed volume and the subsequent observation of the spatial distribution of chemical species at the atomic scale are thus made possible. This enables the measurement of local chemical composition in any arbitrary zones of the reconstructed volume at the nanometer scale. Concentration profiles ${ }^{24}$ with a depth resolution better than half an atomic plane can be generated. ${ }^{22}$ More details are available in the following publications. ${ }^{19-21}$ Multilayers analysed by APT are deposited onto pre-patterned substrates consisting of an assembly of flat-topped Si (100) posts prior etching procedure. These substrates with posts of $100 \mu \mathrm{m}$ height and $10 \times 10 \mu \mathrm{m}^{2}$ area are obtained after patterning of the $\mathrm{Si}$ wafer by a Bosch process. ${ }^{25,26}$ Following the initial field cooling from $250{ }^{\circ} \mathrm{C}$ down to room temperature, the samples were further annealed at $300,400,500$, and $700^{\circ} \mathrm{C}$ for $1 \mathrm{~h}$. Their temperature was subsequently decreased down to room temperature. The heat treatments were performed under vacuum $\left(10^{-2} \mathrm{~Pa}\right)$ in a resistive furnace. APT specimens were subsequently etched in the shape of sharp needles using a focused ion beam (FIB). APT samples were analyzed by laser assisted tomographic atom probe (LATAP) at $80 \mathrm{~K}$ in an ultrahigh vacuum chamber at a pressure of $10^{-8} \mathrm{~Pa}$. The femtosecond laser pulse system used was an amplified ytterbium-doped laser (AMPLITUDE SYSTEM s-pulse) with a pulse length of $350 \mathrm{fs}$. The wavelength was fixed at $515 \mathrm{~nm}$.

\section{RESULTS AND DISCUSSION}

\section{A. APT investigations}

Multilayers investigated by APT consist of IrMn (80 at. $\%$ of $\mathrm{Mn}$ ) deposited on three $\mathrm{Pt} / \mathrm{Co}$ bi-layers, $\mathrm{Pt}$ being the first deposited layer of the $(\mathrm{Pt} / \mathrm{Co})_{3} / \mathrm{IrMn}$ sequence. Let us define these layers as $\mathrm{Pt}_{(1)}, \mathrm{Co}_{(1)}, \mathrm{Pt}_{(2)}, \mathrm{Co}_{(2)}, \mathrm{Pt}_{(3)}, \mathrm{Co}_{(3)}$, the subscript defining the order of deposition of $\mathrm{Pt} / \mathrm{Co}$ bi-layers. The spatial distributions of $\mathrm{Pt}, \mathrm{Co}, \mathrm{Ir}$, and $\mathrm{Mn}$ atoms in such $\left[(\mathrm{Pt} / \mathrm{Co})_{3} / \mathrm{IrMn}\right]_{7}$ multilayers annealed at 300 and $400{ }^{\circ} \mathrm{C}$ are depicted in Fig. 1. Each dot corresponds to a single atom of a given nature (Pt, Co, Mn, Ir). The 3D image is oriented in order to show the interfaces in cross section, i.e., perpendicular to the plane of view.

These maps show that the nominal stacking sequence is preserved after annealing at both 300 and $400{ }^{\circ} \mathrm{C}$. Two complete sequences are presented. The three Co layers remain well distinct. Composition profiles (Fig. 2) confirm that the Co layers contain a large amount of Pt. Considering the very low thickness of the Co layer, we infer that Co adopts the fcc structure of the Pt layers as already shown in Ref. 27. The presence of a large amount of $\mathrm{Pt}$ in Co layers can be explained by considering the large miscibility of $\mathrm{Pt}$ in fcc Co observed in the Co-Pt phase diagram. ${ }^{28}$ The composition of

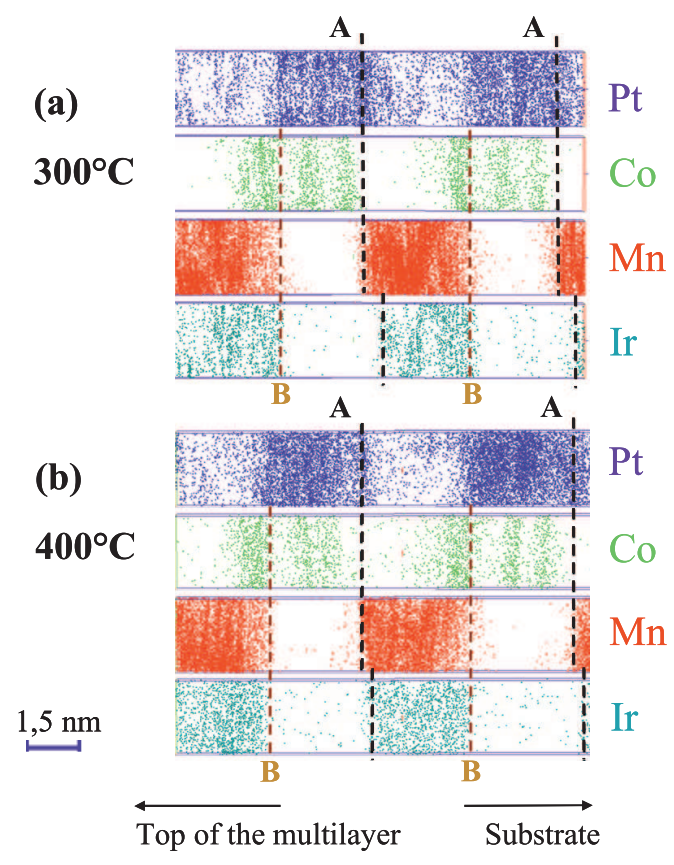

FIG. 1. APT elemental maps showing the distribution of Pt, Co, Ir, and Mn atoms in $\left[(\mathrm{Pt} / \mathrm{Co})_{3} / \mathrm{IrMn}\right]_{7}$ multilayered samples annealed at 300 and $400{ }^{\circ} \mathrm{C}$.

the IrMn layer is close to $20-80$ at. $\%$ as expected from that of the alloy target.

For the sake of clarity, let us define the two distinct interfaces labelled, respectively, as IrMn/Pt (A in Fig. 1, Pt deposited on IrMn) and $\mathrm{Co}_{(3)} / \mathrm{IrMn}$ (B in Fig. 1, IrMn deposited on
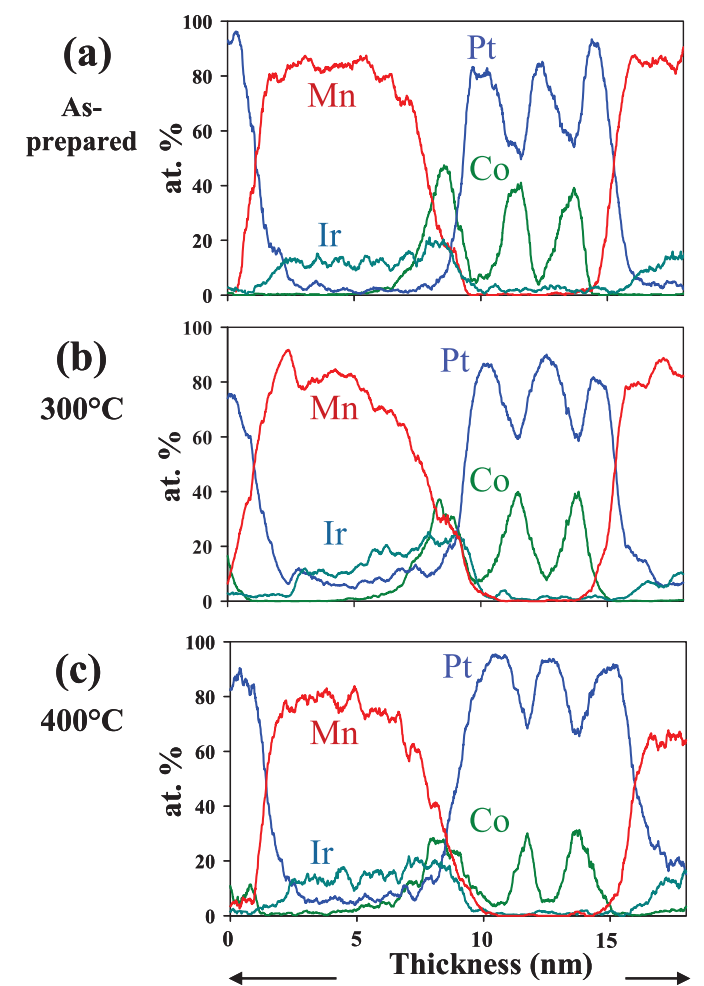

Top of the multilayer Substrate

FIG. 2. Concentration profiles related to $\mathrm{Pt}$, $\mathrm{Co}$, Ir, and $\mathrm{Mn}$ atoms of one sequence of the $\left[(\mathrm{Pt} / \mathrm{Co})_{3} / \mathrm{IrMn}\right]_{7}$ multilayer for three samples before and after annealing at 300 and $400^{\circ} \mathrm{C}$. 
the third Co layer $\left.\mathrm{Co}_{(3)}\right)$. A careful examination of images at $300{ }^{\circ} \mathrm{C}$ (Fig. 1(a)) reveals a diffuse MnPt transient zone at the IrMn/Pt interfaces (three such zones are visible in Fig. 1(a)) that is Mn-enriched (observed as a shift between the Mn and Ir interfaces) The observed migration of $\mathrm{Mn}$ in $\mathrm{Pt}_{(1)}$ layer looks less pronounced at $400{ }^{\circ} \mathrm{C}$ than at $300^{\circ} \mathrm{C}$. Such a migration is only apparent but not due to annealing effect. It is related to the contrast in evaporation fields between $\mathrm{Pt}$ (high field) and Mn (low field) which induce a local magnification effect. $^{23}$

Let us now focus on the $\mathrm{Co}_{(3)} / \mathrm{IrMn}$ interfaces. In contrast to the IrMn/Pt interfaces (A in Fig. 1), the $\mathrm{Co}_{(3)} / \mathrm{IrMn}$ interfaces (B in Fig. 1) exhibit a different behaviour. At the $\mathrm{Co}_{(3)} / \mathrm{IrMn}$ interface, $\mathrm{Mn}$ and $\mathrm{Co}$ are evaporated at the same field. The contrast in evaporation fields between Co (evaporated under low field) of the $\mathrm{Co}_{(3)}$ layer and $\mathrm{Pt}$ (evaporated under high field) of the $\mathrm{Pt}_{(3)}$ layer does not induce any apparent mixing at this interface. The similar position of $\mathrm{Mn}$ and Ir at $\mathrm{Co}_{(3)} / \mathrm{IrMn}$ interfaces at both 300 and $400{ }^{\circ} \mathrm{C}$ supports the idea that $\mathrm{Co}$ mainly diffuses into $\mathrm{IrMn}$. The larger spacing between the two last Co layers $\left(\mathrm{Co}_{(2)}-\mathrm{Co}_{(3)}\right)$ is in favour of this scenario. Note that the IrMn zone ends up at the Codepleted $\mathrm{Pt}_{(3)}$ layer, confirming the role of $\mathrm{Pt}$ as a diffusion barrier preventing interdiffusion at $\mathrm{Co}_{(3)} / \mathrm{IrMn}$ interfaces. ${ }^{19,20}$

The comparison between the concentration profiles (Fig. 3) related to the three states (as prepared (i.e., annealed at $250{ }^{\circ} \mathrm{C}$ ), further annealed at 300 and $400^{\circ} \mathrm{C}$ ) at the $\mathrm{Co}_{(3)} /$ IrMn interface reveals a significant evolution with annealing. The peak concentration in $\mathrm{Co}_{(3)}$ layer decreases from 50 to 30 at. $\%$ when increasing annealing temperature. In addition, the observed shift of the Co peak towards the IrMn layer (dotted line) suggests that Co atoms have diffused into the

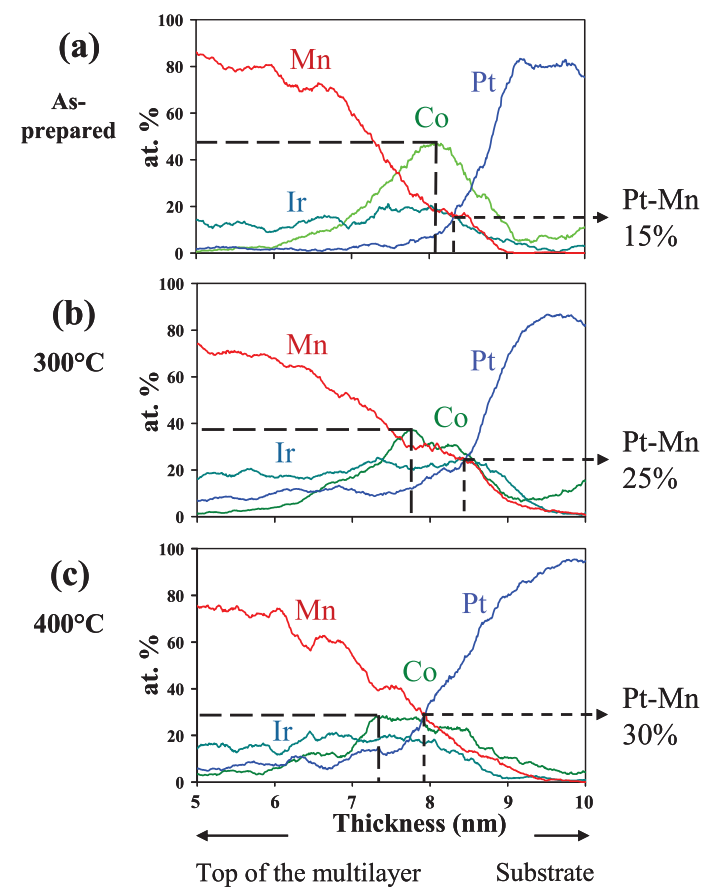

FIG. 3. Concentration profiles related to $\mathrm{Pt}$, Co, Ir, and $\mathrm{Mn}$ atoms at the $\mathrm{Co}_{(3)} / \mathrm{IrMn}$ interface of three $\left[(\mathrm{Pt} / \mathrm{Co})_{3} / \mathrm{IrMn}\right]_{7}$ multilayered samples before and after annealing at 300 and $400{ }^{\circ} \mathrm{C}$.
IrMn layer during annealing. A closer examination of Mn and Pt profiles shows that they cross at a level increasing from 15 at. $\%$ (before annealing) to 30 at. $\%\left(400{ }^{\circ} \mathrm{C}\right.$ annealing), suggesting that $\mathrm{Mn}$ diffuses towards the $\mathrm{Pt}_{(3)}$ layer during annealing.

Elemental maps related to samples annealed at 500 and $700{ }^{\circ} \mathrm{C}$ (Fig. 4) reveal both a drastic change in the structure of the multilayer compared to lower annealing temperatures (Figs. 1-3). Mn diffuses out of the IrMn layer and the characteristic Pt/Co stacking sequence (Co-poor/Co-rich, see Fig. 1) disappears. After annealing at $500{ }^{\circ} \mathrm{C}$ (Fig. 4(a)), Mn atoms appear almost homogeneously distributed over the whole multilayer. A faint depletion of Mn more clearly appears in the right-side of the Ir-rich region, suggesting that $\mathrm{Mn}$ atoms begin diffusing out of the IrMn layers. Unexpectedly, the IrMn layers now contain Co. IrMn layers are expected to be Pt-depleted. However, this behaviour appears less clear for $500^{\circ} \mathrm{C}$ annealing, particularly for the left-side IrMn layer of Fig. 4(a). This presence of Pt in the left-side IrMn layer, not coherent with other results, is not understood and remains an open question. The elemental map displayed in Fig. 4 for the PtMn region and after annealing at $500^{\circ} \mathrm{C}$ would be consistent with a fcc crystalline structure of PtMn $(\mathrm{a}=0.392 \mathrm{~nm})$. (111) planes containing Pt and $\mathrm{Mn}$ indeed have a spacing close to that expected $\left(\mathrm{d}_{111} \sim 0.23 \mathrm{~nm}\right)$ (Fig. 5).

The general trend clarifies at $700{ }^{\circ} \mathrm{C}$ (Fig. 4(b)). One observes the alternation of PtMn layers with IrCo. Mn and Co have exchanged their role. IrMn layers are now Mndepleted and have a considerably larger Co content, to the expense of the three initial $\mathrm{Pt} / \mathrm{Co}$ bi-layers that are now Codepleted and Mn-enriched. Concentration profiles related to samples annealed at $700{ }^{\circ} \mathrm{C}$ confirm the previous observations (Fig. 6). The IrCo layers alternate with thicker PtMn

(a)

$500^{\circ} \mathrm{C}$
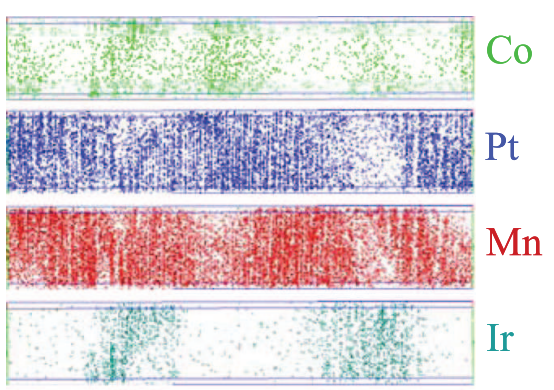

(b)

$700^{\circ} \mathrm{C}$
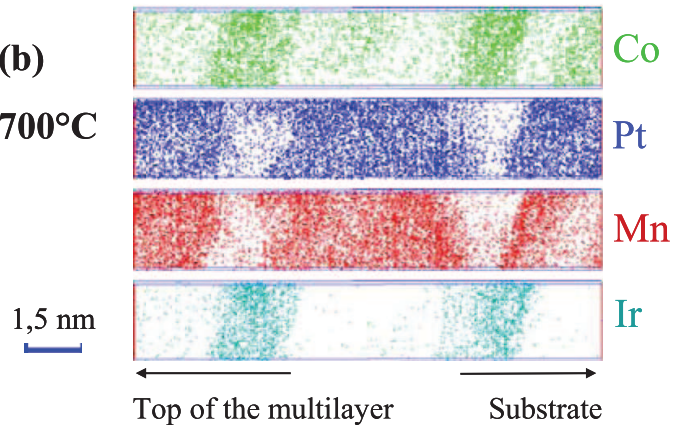

FIG. 4. APT elemental maps showing the distribution of Pt, Co, Ir, and Mn atoms in $\left[(\mathrm{Pt} / \mathrm{Co})_{3} / \mathrm{IrMn}\right]_{7}$ multilayered samples annealed at 500 and $700{ }^{\circ} \mathrm{C}$. 


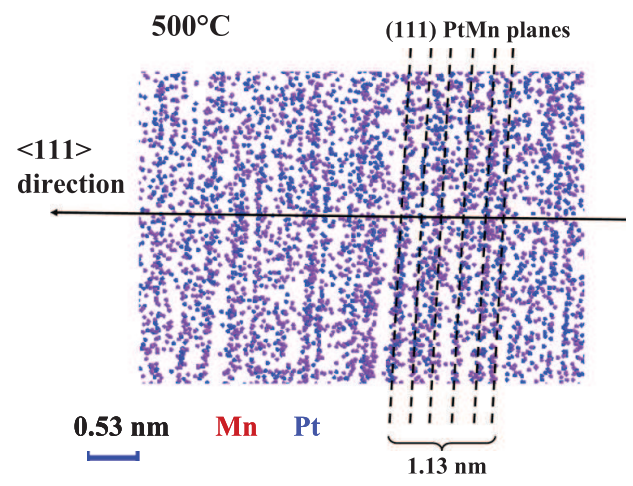

FIG. 5. APT elemental maps showing the distribution of Pt and Mn atoms in the PtMn region (see Fig. 3) of $\left[(\mathrm{Pt} / \mathrm{Co})_{3} / \mathrm{IrMn}\right]_{7}$ multilayered samples annealed at $500^{\circ} \mathrm{C}$. (111) atomic planes containing both Pt and Mn atoms are imaged.

layers. The latter are thicker than IrCo layers and replace the former three $\mathrm{Pt} / \mathrm{Co}$ bi-layers. The respective thicknesses of $\mathrm{PtMn}$ and IrCo layers are consistent with concentrations. $\mathrm{Pt}$ and Mn concentrations in the PtMn zone (the former three $\mathrm{Pt} / \mathrm{Co}$ bi-layers) are both close to 45 at. \% (peak level) with a remaining amount of Co close to 10 at. \%. There is almost no Ir in PtMn layers, confirming that Ir has not diffused out of the IrMn layer. Ir and Co concentrations are both close to 40 at. \% in IrCo zones in which Pt and Mn content is close to 10 at. $\%$.

\section{B. Discussion}

The above results show that the $(\mathrm{Pt} / \mathrm{Co})_{3} / \mathrm{IrMn}$ stacking sequence is preserved up to annealing at $400^{\circ} \mathrm{C}$. In contrast, an almost complete destruction of the multilayered structure takes place when annealing at higher temperatures (500 and $700^{\circ} \mathrm{C}$ ). In addition, an estimate of diffusion lengths after $1 \mathrm{~h}\left(\rho \sim \sqrt{6 \mathrm{Dt}}\right.$, where $\mathrm{D}$ are the diffusion constants ${ }^{29}$ of $\mathrm{Pt}$ in Co or Co in $\mathrm{Pt}$ and the annealing time) shows that atoms migrate over distances of the order of $1 \mathrm{~nm}$ or larger only for temperatures reaching $500{ }^{\circ} \mathrm{C} \quad(\rho \sim 0.5 \mathrm{~nm})$ or higher $\left(\rho \sim 30 \mathrm{~nm}\right.$ at $700^{\circ} \mathrm{C}$ ). The diffusion length of $\mathrm{Pt}$ in $\mathrm{Co}$ at $300{ }^{\circ} \mathrm{C}(\rho<0.1 \mathrm{~nm})$ or $400{ }^{\circ} \mathrm{C}$ remains very small. However, lattice defects produced during the deposition procedure are

$700{ }^{\circ} \mathrm{C}$

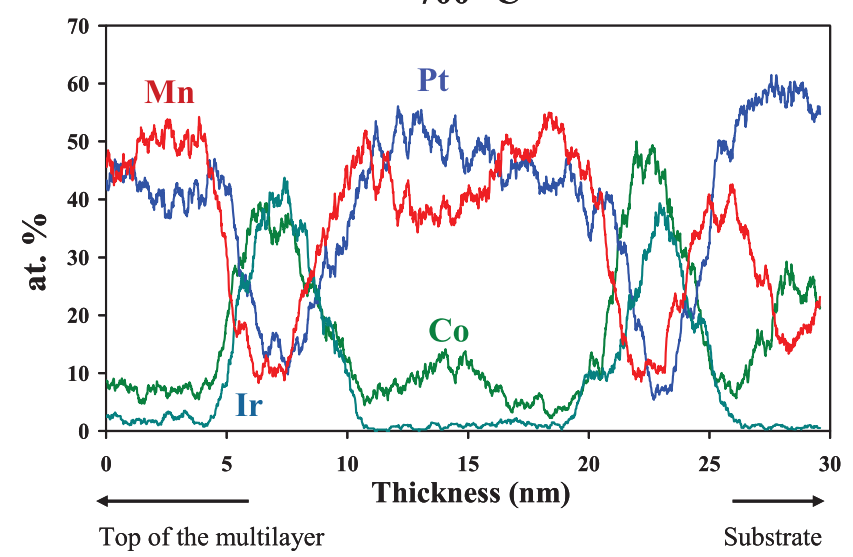

FIG. 6. Pt, Co, Ir, and $\mathrm{Mn}$ concentration profiles related to $\left[(\mathrm{Pt} / \mathrm{Co})_{3} / \mathrm{IrMn}\right]_{7}$ multilayered samples annealed at $700^{\circ} \mathrm{C}$. likely to increase the mobility. Surface intermixing during Pt deposition on Co by sputtering (as-deposited state) can also be at the origin of the presence of Pt in the Co layers. ${ }^{30}$ This Co-Pt intermixing was already evidenced in similar multilayers in our previous studies. ${ }^{19-21,23}$

APT experiments (Fig. 4) reveal a cross diffusion of Mn and Co. A rough estimate of the diffusion distances shows that $\mathrm{Mn}$ migrates in Co over $0.4 \mathrm{~nm}$ at $500^{\circ} \mathrm{C}$ and $150 \mathrm{~nm}$ at $700{ }^{\circ} \mathrm{C}$. The mobility is thus very small at 300 and $400{ }^{\circ} \mathrm{C}$. Ir, and $\mathrm{Pt}$ to a smaller extent, are refractory elements that should have lower mobilities ("cold" diffusers when taking the reduced temperature $T / T_{m}$ into account where $T_{m}$ is the melting temperature). They are therefore much less affected and move much less than Mn and Co ("hot" diffusers) that have lower melting temperatures. IrMn changes into $\mathrm{IrCo}$ while $(\mathrm{Pt} / \mathrm{Co})_{3}$ turns into a PtMn zone with a remaining amount of $\mathrm{Co}$ of about 10 at. \%. Mn atoms diffuse out of IrMn towards the PtCo zone that becomes depleted in Co which in turn diffuses into the IrMn layer. Ir atoms were not observed to mix up with Pt atoms in the PtMn zone. An additional reason related to the atomic mobility is the Ir-Pt low mutual miscibility. Pt-Ir phase diagram indeed exhibits a large miscibility gap for temperatures below $900^{\circ} \mathrm{C}$.

The presence of an IrCo layer instead of $\mathrm{IrMn}$ for $\mathrm{T}=500^{\circ} \mathrm{C}-700^{\circ} \mathrm{C}$ suggests a strong chemical affinity between Ir and Co atoms. This affinity is supported by the equilibrium phase diagram that exhibits a large mutual miscibility of fcc Ir with Co when temperature exceeds $422^{\circ} \mathrm{C}$ ( $\alpha$-fcc solid solution). Similarly, APT results suggest that Pt atoms have a strong chemical affinity with $\mathrm{Mn}$. In contrast, the Pt-Mn phase diagram reveals a very low miscibility (Mn has a more complex structure than fcc Pt). However, several ordered intermetallic phases exist among them, as for example the $\beta_{1} \mathrm{Pt}-\mathrm{Mn}$ ordered phase that exists in a large concentration range $(33-60$ at. $\%$ of $P t)$ within which falls the observed Pt concentration (50 at. \%). This could explain the formation of the observed PtMn zone despite their low mutual solubility.

In $\left(\mathrm{Pt}_{2 \mathrm{~nm}} / \mathrm{Co}_{0.4 \mathrm{~nm}}\right)_{3} / \mathrm{Pt}_{0.4 \mathrm{~nm}} / \mathrm{IrMn}_{7 \mathrm{~nm}}$ multilayers, we have shown that the Pt spacer acts as a diffusion barrier, which limits Mn diffusion into the Co layer in contact with IrMn and also contributes to the reinforcement of the perpendicular anisotropy. ${ }^{13,19-21}$ The strong mutual Mn-Pt affinity could explain that, during deposition, Mn atoms deposited on the Pt spacer are chemically stabilized, thanks to the Mn$\mathrm{Pt}$ affinity, preventing the propagation of $\mathrm{Mn}$ atoms towards the $\mathrm{Co}_{(3)}$ layer. In these conditions, the Pt spacer would not only act as a diffusion barrier, but also as a Mn pinning layer.

\section{CONCLUSION}

The effect of annealing on the structural stability of $\left(\mathrm{Pt}_{2 \mathrm{~nm}} / \mathrm{Co}_{0.4 \mathrm{~nm}}\right)_{3} / \mathrm{IrMn}_{7 \mathrm{~nm}}$ multilayers has been investigated using APT. The composition of individual layers (Pt, Co-rich layers, IrMn) was measured after annealing the as prepared state at $300,400,500$, and $700^{\circ} \mathrm{C}$. APT results show that the $(\mathrm{Pt} / \mathrm{Co})_{3} / \mathrm{IrMn}$ stacking sequence is preserved up to $400^{\circ} \mathrm{C}$. However, Pt is observed in Co layers despite 
this element is predicted to diffuse over very small distances $(<0.1 \mathrm{~nm})$ at such low temperatures (Co layers are thus rather CoPt mixed layers). Lattice defects in supersaturation caused by the deposition process may account for this rather surprising result. Results show an almost complete destruction of the multilayered structure after annealing at higher temperatures $\left(500\right.$ and $\left.700{ }^{\circ} \mathrm{C}\right)$. Pt-rich layers are no more observed to alternate with mixed PtCo layers $\left((\mathrm{Pt} / \mathrm{Co})_{3}\right)$. The whole stack is transformed into an $\mathrm{IrCo} / \mathrm{PtMn}$ bilayer. This shows that Co diffuses towards IrMn layer and conversely, $\mathrm{Mn}$ migrates out of the IrMn region and forms a new PtMn-enriched phase (instead of $\left.(\mathrm{Pt} / \mathrm{Co})_{3}\right)$ that is tentatively interpreted as an ordered $\beta_{1}$ phase. Diffusion of Co and Mn becomes important only when temperature approaches $500{ }^{\circ} \mathrm{C}$. Results are well accounted for by arguments considering the Co-Ir and Pt-Mn phase diagrams which show a large Co-Ir mutual miscibility for $\mathrm{T}>422^{\circ} \mathrm{C}$ and the formation of a $\beta_{1}$ Pt-Mn ordered phase with a large domain of stability.

${ }^{1}$ W. H. Meiklejohn and C. P. Bean, Phys. Rev. 102, 1413 (1956).

${ }^{2}$ J. Nogués and I. K. Schuller, J. Magn. Magn. Mater. 192, 203 (1999).

${ }^{3}$ A. E. Berkowitz and K. Takano, J. Magn. Magn. Mater. 200, 552 (1999).

${ }^{4}$ R. L. Stamps, J. Phys. D 33, R247 (2000).

${ }^{5}$ M. Kiwi, J. Magn. Magn. Mater. 234, 584 (2001).

${ }^{6}$ B. Dieny, V. S. Speriosu, S. S. P. Parkin, B. A. Gurney, D. R. Wilhoit, and D. Mauri, Phys. Rev. B 43, 1297 (1991).

${ }^{7}$ S. Maat, K. Takano, S. S. P. Parkin, and E. E. Fullerton, Phys. Rev. Lett. 87, 087202 (2001).

${ }^{8}$ F. Garcia, G. Casali, S. Auffret, B. Rodmacq, and B. Dieny, J. Appl. Phys. 91, 6905 (2002).

${ }^{9}$ C. H. Marrows, Phys. Rev. B 68, 012405 (2003).
${ }^{10}$ J. Sort, B. Dieny, M. Fraune, C. Koenig, F. Lunnebach, B. Beschoten, and G. Güntherodt, Appl. Phys. Lett. 84, 3696 (2004).

${ }^{11}$ B. Kagerer, C. Binek, and W. Kleemann, J. Magn. Magn. Mater. 217, 139 (2000).

${ }^{12}$ F. Garcia, J. Sort, B. Rodmacq, S. Auffret, and B. Dieny, Appl. Phys. Lett. 83, 3537 (2003).

${ }^{13}$ J. Sort, V. Baltz, F. Garcia, B. Rodmacq, and B. Dieny, Phys. Rev. B 71, 054411 (2005).

${ }^{14}$ S. Hashimoto, Y. Ochiai, and K. Aso, J. Appl. Phys. 66, 4909 (1989).

${ }^{15}$ P. F. Carcia, J. Appl. Phys. 63, 5066 (1988).

${ }^{16}$ S. V. Dijken, J. Moritz, and J. M. D. Coey, J. Appl. Phys. 97, 063907 (2005).

${ }^{17}$ J. Sort, F. Garcia, B. Rodmacq, S. Auffret, and B. Dieny, J. Magn. Magn. Mater 272-276, 355 (2004).

${ }^{18}$ J. Moritz, S. van Dijken, and J. M. D. Coey, Eur. Phys. 45, 191 (2005).

${ }^{19}$ A. Zarefy, R. Lardé, L. Lechevallier, F. Cuvilly, J. M. Le Breton, V. Baltz, B. Rodmacq, and B. Dieny, J. Appl. Phys. 105, 103912 (2009).

${ }^{20}$ L. Lechevallier, A. Zarefy, R. Lardé, H. Chiron, J. M. Le Breton, V. Baltz, B. Rodmacq, and B. Dieny, Phys. Rev. B 79, 174434 (2009).

${ }^{21}$ A. Zarefy, L. Lechevallier, R. Lardé, H. Chiron, J. M. Le Breton, V. Baltz, B. Rodmacq, and B. Dieny, J. Phys. D: Appl. Phys. 43, 215004 (2010).

${ }^{22}$ B. Gault, F. Vurpillot, A. Vella, M. Gilbert, A. Menand, D. Blavette, and B. Deconihout, Rev. Sci. Instrum. 77, 043705 (2006).

${ }^{23}$ R. Lardé, L. Lechevallier, A. Zarefy, A. Bostel, J. Juraszek, J. M. Le Breton, B. Rodmacq, and B. Dieny, J. Appl. Phys. 105, 084307 (2009).

${ }^{24}$ P. Bas, A. Bostel, B. Deconihout, and D. Blavette, Appl. Surf. Sci. 87-88, 298 (1995).

${ }^{25}$ D. J. Larson, A. K. Petford-Long, Y. Q. Ma, and A. Cerezo, Acta Mater. 52, 2847 (2004).

${ }^{26}$ A. A. Ayon, R. Braff, C. C. Lin, H. H. Swain, and M. A. Schmidt, J. Electrochem. Soc. 146(1), 339 (1999).

${ }^{27}$ N. Nakajima, T. Koide, T. Shidara, H. Miyauchi, H. Fukutani, A. Fujimori, K. Iio, T. Katayama, M. Nyvlt, and Y. Suzuki, Phys. Rev. Lett. 81, 5229 (1998).

${ }^{28}$ Binary Alloys Phase Diagrams V1 and V2, edited by T. B. Massalski (American Society of Metals, 1986).

${ }^{29}$ Diffusion in Solid Metals and Alloys V26, Landolt-Börnstein, edited by O. Madelung (Springer-Verlag, 1990).

${ }^{30}$ T. Bigault, F. Bocquet, S. Labat, O. Thomas, and H. Renevier, Phys. Rev. B 64, 125414 (2001). 